\title{
ABORDAGEM POLÍTICO-NORMATIVA DA EDUCAÇÃO ESPECIAL NOS PAÍSES MEMBROS DO MERCOSUL
}

\author{
ABORDAJE POLÍTICO-NORMATIVO DE LA EDUCACIÓN ESPECIAL EN LOS \\ PAÍSES MIEMBROS DEL MERCOSUR
}

\author{
POLITICAL-NORMATIVE APPROACH TO SPECIAL EDUCATION IN MERCOSUR \\ MEMBER COUNTRIES
}

\author{
Albert Vinicius ICASATTI ${ }^{1}$ \\ Washington Cesar Shoiti NOZU ${ }^{2}$
}

RESUMO: Este texto visa analisar o discurso da educação inclusiva materializado na documentação educacional do Mercado Comum do Sul (MERCOSUL) e, particularmente, a abordagem político-normativa sobre Educação Especial nos países membros do bloco, de modo a destacar os sujeitos considerados com necessidades educacionais específicas e os espaçostempos definidos para sua escolarização e para a prestação de serviços especializados. Trata-se de uma investigação que fez uso de fontes escritas documentais, a saber: Planos de Ação do Setor Educacional do MERCOSUL (2001-2005; 2006-2010; 2011-2015; 2016-2020); Constituições, leis educacionais gerais e textos políticos voltados especificamente à Educação Especial dos países membros do MERCOSUL (Argentina, Brasil, Paraguai, Uruguai e Venezuela). Os resultados foram dispostos em duas seções: a) Educação Inclusiva no MERCOSUL; b) Configurações da Educação Especial nos Países Membros do MERCOSUL. Conclui-se que os países que integram o bloco adotam a perspectiva da educação inclusiva, tal como sugerem fluidamente os Planos de Ação do Setor Educacional. Quanto à abordagem da Educação Especial na documentação interna dos países, evidencia-se a tendência de escolarização de alunos compreendidos por esta modalidade de ensino nas classes comuns das escolas regulares. No entanto, observam-se diferenças entre os países quanto à definição dos alunos atendidos pela Educação Especial. Nota-se também, na documentação interna dos países, uma heterogeneidade quanto aos espaços e aos tempos de oferta da Educação Especial, entretanto a produção textual, neste ponto, é marcada por lacunas, haja vista que ou não apontou esses aspectos ou o fez de forma genérica, superficial e/ou indeterminável.

PALAVRAS-CHAVE: Direito à educação. Educação inclusiva. Educação especial. Diversidade.

RESUMEN: Este texto pretende analizar el discurso de la educación inclusiva materializada en la documentación educativa del Mercado Común del Sur (MERCOSUR) y, particularmente, el enfoque político-normativo sobre Educación Especial en los países miembros del bloque, com el fin de destacar los sujetos considerados con necesidades educativas específicas y los

\footnotetext{
${ }^{1}$ Universidade Federal da Grande Dourados (UFGD, Dourados - MS - Brasil. Mestre em Fronteiras e Direitos Humanos. ORCID: https://orcid.org/0000-0002-0235-246X. E-mail: albert_ksat@ hotmail.com

${ }^{2}$ Universidade Federal da Grande Dourados (UFGD), Dourados - MS - Brasil. Docente do Programa de PósGraduação em Fronteiras e Direitos Humanos - UFGD. Doutor em Educação. ORCID: https://orcid.org/00000003-1942-0390. E-mail: wcsn1984@yahoo.com.br
} 
espacios-tiempos definidos para su escolarización y prestación de servicios especializados. Se trata de una investigación que hizo uso de las seguientes fuentes: Planes de Acción del Sector Educativo del MERCOSUR (2001-2005; 2006-2010; 2011-2015; 2016-2020); Constituciones, leyes educativas generales y textos políticos dirigidos específicamente a la Educación Especial de los países miembros del MERCOSUR (Argentina, Brasil, Paraguay, Uruguay y Venezuela). Los resultados fueron dispuestos en dos secciones: a) Educación Inclusiva en el MERCOSUR; b) Configuraciones de la Educación Especial en los Países Miembros del MERCOSUR. Se concluye que los países que integran el bloque adoptan la perspectiva de la educación inclusiva, tal como sugieren fluidamente los Planes de Acción del Sector Educacional. En cuanto al abordaje de la Educación Especial en la documentación interna de los países, se evidencia la tendencia de escolarización de alumnos comprendidos por esta modalidad de enseñanza en las clases comunes de las escuelas regulares. Sin embargo, se observan diferencias entre los países acerca de la definición de los alumnos atendidos por la Educación Especial. Se observa también, en la documentación interna de los países, una heterogeneidad en cuanto a los espacios y los tiempos de oferta de la Educación Especial, sin embargo la producción textual, en este punto, está marcada por lagunas, ya que o no apunta estos aspectos o lo ha hecho de forma genérica, superficial y / o indeterminable.

PALABRAS CLAVE: Derecho a la educación. Educación inclusiva. Educación especial. Diversidad.

ABSTRACT: This text aims to analyze the discourse of inclusive education materialized in the educational documentation of the Common Market of the South (MERCOSUR), and particularly the political-normative approach on Special Education in the member countries of the bloc, in order to highlight the subjects considered with specific educational needs and the space-times defined for their schooling and for the provision of specialized services. It is an investigation that made use of documentary written sources, namely: Action Plans of the Educational Sector of MERCOSUR (2001-2005, 2006-2010, 2011-2015, 2016-2020); Constitutions, general educational laws and political texts specifically addressed to the Special Education of MERCOSUR member countries (Argentina, Brazil, Paraguay, Uruguay and Venezuela). The results were divided into two sections: a) Inclusive Education in MERCOSUR; b) Special Education Settings in MERCOSUR Member Countries. It is concluded that the countries that are part of the bloc adopt the perspective of inclusive education, as the Education Sector Action Plans suggest. Regarding the Special Education approach in the internal documentation of the countries, it is evident the tendency of schooling of students understood by this modality of education in the common classes of the regular schools. However, there are differences among countries regarding the definition of students attended by Special Education. It is also noted in the internal documentation of the countries, a heterogeneid However, textual production at this point is marked by gaps, given that it has not pointed out these aspects or has done so in a general, superficial and / or indeterminable way.

KEYWORDS: Right to education. Inclusive education. Special education. Diversity. 


\section{Introdução}

A Declaração Universal dos Direitos Humanos (DUDH) de 1948 consignou a educação no rol das prerrogativas destinadas à tutela da dignidade da pessoa humana. Dada a sua essencialidade para o desenvolvimento do indivíduo e da sociedade, a DUDH recomendou a gratuidade e obrigatoriedade da educação, sobretudo nas etapas elementares. Os signatários do documento comprometeram-se com a sua garantia, considerando, para tanto, o acesso e permanência dos indivíduos nas instituições escolares.

Entretanto, como assinala Bobbio (2004, p. 23, grifos do autor), "o problema fundamental em relação aos direitos do homem, hoje, não é tanto o de justificá-los, mas o de protegêe-los. Trata-se de um problema não filosófico, mas político". Assim, diante do diagnóstico da situação da educação mundial, a partir da década de 1990, a Organização das Nações Unidas para a Educação, a Ciência e a Cultura (UNESCO) passou a promover, no contexto da globalização e do neoliberalismo, um movimento denominado "Educação para Todos", materializado nas Declarações de Jomtien (1990), Dakar (2000) e Incheon (2015).

$\mathrm{Na}$ esteira desse movimento, a luta por uma educação inclusiva passou a ganhar destaque, sobretudo com a Declaração de Salamanca (1994), enfatizando a necessidade das escolas oportunizarem o atendimento a todas as pessoas, independentemente de suas condições físicas, sensoriais, intelectuais, culturais, etárias, socioeconômicas, étnico-raciais, de gênero e diversidade sexual e de origem.

Este discurso de universalização da educação articula-se às reformas neoliberais, visando ajustar os países às exigências da reestruturação global da economia (SHIROMA; MORAES; EVANGELISTA, 2011). Nessa direção, a educação adjetivada de inclusiva possibilita uma inserção interessante ao mercado: que sujeitos marginalizados, improdutivos e deficientes possam ser (con)formados em sujeitos "incluídos", produtivos e eficientes ao sistema de produção.

Além disso, é preciso sinalizar que o conceito de educação inclusiva é polissêmico. Ainscow (2009) indica a inexistência de consenso na definição de educação inclusiva e elenca cinco concepções recorrentes no âmbito mundial: a) como proposta adstrita aos alunos públicoalvo da Educação Especial; b) como resposta a exclusões de alunos indisciplinados; c) como atenção a todos os grupos vulneráveis à exclusão; d) como forma de combate ao sistema de escolas classificatórias, organizadas com base nas capacidades dos alunos; e) como educação para todos. 
Considerando as relações políticas globais, regionais e nacionais, o presente artigo objetiva analisar o discurso da educação inclusiva materializado na documentação educacional do Mercado Comum do Sul (MERCOSUL) e, particularmente, a abordagem político-normativa sobre Educação Especial nos países membros do bloco, de modo a destacar os sujeitos considerados com necessidades educacionais específicas e os espaços-tempos definidos para sua escolarização e para a prestação de serviços especializados.

O MERCOSUL foi criado com a incumbência de impulsionar a economia dos países sul-americanos e de promover a integração socioeconômica da América Latina. O bloco se pauta na busca pela “[...] prosperidade econômica com democracia, estabilidade política e respeito aos direitos humanos e liberdades fundamentais" (MERCOSUL, 2019). Argentina, Brasil, Paraguai, Uruguai e Venezuela são países membros plenos. A Venezuela foi suspensa em dezembro de 2016, sendo esta sua condição atual. Todos os demais países sul-americanos aderiram ao MERCOSUL como Estados associados.

O bloco reconhece a importância da educação no processo de integração regional, legitimando-a como recurso criador de oportunidades que favorecem o desenvolvimento social, econômico e humano sustentável. Foi o que fundamentou a criação do Setor Educacional do MERCOSUL (SEM), órgão no qual são elaboradas e administradas políticas educacionais para o bloco. Com o SEM, objetiva-se construir um espaço educacional alinhado, com amparo em políticas que combinem educação e integração do MERCOSUL, foco principal do bloco, incentivando a formação de uma identidade regional.

Para o exercício metodológico do trabalho, foi realizada uma pesquisa documental. Conforme Marconi e Lakatos (2003), a pesquisa documental trabalha com fontes primárias, caracterizadas, neste trabalho, como documentação indireta em virtude da forma como se dá o levantamento dos dados e de sua adstrição a documentos.

O corpus documental analisado foi constituído por: a) Planos de Ação do SEM (20012005; 2006-2010; 2011-2015; 2016-2020); b) Constituições, leis educacionais que dispõem sobre o sistema educativo geral e textos político-normativos dos países membros do MERCOSUL que tratam especificamente da Educação Especial.

Os documentos foram selecionados, lidos e devidamente fichados. Os dados foram organizados em tabelas, as quais foram preenchidas com recortes dos documentos estudados, com trechos pertinentes ao objeto de análise, qual seja, o discurso da educação inclusiva no âmbito do MERCOSUL e a abordagem da Educação Especial nas produções políticonormativas dos países que integram o bloco. 
$\mathrm{O}$ artigo está organizado em duas seções. A primeira seção, Educação Inclusiva no MERCOSUL, é destinada à apresentação da veiculação da educação inclusiva nos quatro últimos Planos de Ação elaborados pelo SEM.

A segunda seção, Configurações da Educação Especial nos Países Membros do MERCOSUL, por sua vez, enfatizará o direito à educação de estudantes com necessidades educacionais específicas no contexto de cada país vinculado ao bloco econômico aludido. Assim, far-se-ão problematizações dos dados encontrados nos documentos político-normativos nacionais, de modo a provocar reflexões sobre os sujeitos e os tempos-espaços da Educação Especial em cada país membro do MERCOSUL.

\section{Educação Inclusiva no MERCOSUL}

Reconhecendo o papel fundamental da educação no impulsionamento da economia, por qualificar os recursos humanos, possibilitando que as pessoas logrem empregos e, consequentemente, participem ativamente do mercado, e tendo por objetivo fortalecer o processo de integração regional, foi criado, em dezembro de 1991, o Setor Educacional do MERCOSUL (SEM), encabeçado pela Reunião de Ministros de Educação, que, por sua vez, foi concebido pelo Conselho do Mercado Comum através da Decisão 07/1991 (MATEUS, 2008; SOUZA, 2017).

O SEM está associado e subordinado ao Conselho do Mercado Comum (CMC) e é nele que são desenvolvidos os Programas Anuais de Atividades e os Planos de Ação, documentos nos quais estão as propostas de políticas educacionais comuns para os Estados-partes, que visam garantir, por meio de estratégias e metas, um espaço educacional integrado (SOUZA, 2017). Seu Regulamento Interno é composto por trinta artigos e dispõe sobre a organização de sua estrutura, na qual a Reunião de Ministros da Educação figura como instância máxima e cuja função é propor ao CMC medidas de coordenação das políticas educacionais que representem a visão e a missão do Setor nos Estados-Partes (MATEUS, 2008).

Com o intuito de compreender o modo pelo qual o direito à educação inclusiva tem sido disseminado no âmbito do MERCOSUL, nesta seção serão analisados os quatro últimos Planos de Ação do SEM, quais sejam: Plano Estratégico (2001-2005); Plan del Sector Educativo del MERCOSUR (2006-2010); Plano de Ação do Setor Educacional do MERCOSUL (2011-2015); e Plano de Ação (2016-2020). Isso porque os Planos de Ação elaborados pelo SEM tem a finalidade de, além de estratégias e metas, delinear princípios que se espera serem observados 
e aplicados pelos Estados-Parte, com vistas ao alinhamento do tratamento da temática no contexto do MERCOSUL.

Nota-se uma abordagem crescente a respeito da educação inclusiva, sendo mais tímida no Plano de Ação de 2001-2005 e mais significativa no de 2011-2015. O documento a partir do qual se iniciaram as análises, Plano de Ação de 2001-2005, fez uma breve referência à educação inclusiva em uma das metas estabelecidas para a Educação Básica. Destaca-se que a meta estava inserida no bloco temático que trata do melhoramento da qualidade de educação para todos. Apesar de não elucidar de forma expressa, denota-se que o conceito de educação inclusiva no texto é aquele que se configura na diversidade inerente à espécie humana, ou seja, como um princípio universalizador do direito humano à educação.

Esse mesmo tom foi conferido à educação inclusiva no Plano de Ação válido no período de 2006-2010, que em seu bojo promove o respeito à diversidade, valoriza a multiplicidade cultural dos povos e visa o aperfeiçoamento da qualidade da educação oferecida às pessoas em situação de vulnerabilidade. Nele há inserção da meta que estimula a criação de áreas e modalidades diversas de educação com vistas a alcançar o maior número de pessoas.

No que diz respeito à educação inclusiva, o Plano de Ação de 2011-2015 se revela mais acurado. Advoga em defesa do fortalecimento da política de educação na diversidade, tomandose como referência os direitos humanos. Dada à razão de existência do bloco de promover a integração, unificação e promoção de um ambiente comum entre os países do cone sul, o plano sugere a seus integrantes uma ação conjunta no sentido de harmonizar conceitos e ações políticas para a garantia de educação para todos.

O documento realça, ainda, a relevância do respeito à variedade de necessidades educacionais específicas, com a proposta de estratégias de elevar os debates e discussões sobre as temáticas inerentes aos direitos humanos, às questões de gênero e às populações rurais, indígenas e migrantes, de modo a possibilitar um campo aberto para soluções de problemas enfrentados pelo sistema educacional. O texto reitera as disposições dos planos que o antecederam, especialmente quando propõe metas para a melhoria da qualidade da educação "para todos". Ao mencionar algumas modalidades às quais os países devem se atentar (educação de jovens e adultos, educação à distância, não formal), demonstra sua preocupação com a universalização do ensino. Dentre as orientações preconizadas no Plano de Ação de 2011-2015 estão presentes aquelas que tem como finalidade a promoção de condições de acessibilidade, participação e aprendizagem dos estudantes em maior risco de exclusão dos sistemas educacionais dos países do MERCOSUL. 
Observa-se que o Plano de 2011-2015 enfatiza que a educação é direito de todos, apontando que a educação inclusiva tem por interesse aproximar aqueles grupos vulneráveis afastados ou excluídos do processo de escolarização. Apesar de dar ênfase à Educação Especial, educação indígena e afrodescendente, não foi omissa com relação a outros grupos, também vulneráveis, como a população rural, os migrantes, os excluídos por questões de gênero, dentre outros.

Esse movimento progressivo de atenção à educação inclusiva nos Planos de Ação do SEM não se sustentou, haja vista que o Plano de 2016-2020, em vigência na atualidade, recuou, tendo em vista a existência de apenas uma vaga menção à prioridade de desenvolver oportunidades de inclusão e participação, bem como de atenção às necessidades socioeducativas, o que o distancia substancialmente do documento que o precedeu.

\section{Configurações da Educação Especial nos Países Membros do MERCOSUL}

Na sequência, será analisada a documentação político-normativa referente à Educação Especial nos países membros do MERCOSUL. Este exame seguirá uma análise vertical, partindo da norma mais geral para a mais específica, ou seja, das Constituições às leis educacionais e/ou políticas focalizadas.

Assim, a disposição e a perscrutação dos documentos utilizarão, como critério de organização, a ordem alfabética dos países envolvidos nesse estudo. Nessa direção, serão abordados os textos político-normativos sobre Educação Especial, respectivamente, da Argentina, do Brasil, do Paraguai, do Uruguai e da Venezuela.

Inicialmente, na Argentina, a documentação analisada compreendeu a Constitución Nacional Argentina (1853), a Ley de Educación Nacional (2006), a Resolución CFE $n$. 155/2011 e a Resolución CFE n. 311/2016.

A Constitución Nacional Argentina não faz menção expressa à Educação Especial, tampouco destina capítulo específico para o direito à educação. Refere-se, no entanto, às pessoas com deficiência como um grupo que necessita de atenção especial, mediante ações que lhe assegure igualdade real de oportunidades e possibilite o exercício efetivo de direitos, dentre eles o da educação.

A Educação Especial é reconhecida como modalidade pela Ley de Educación Nacional, Lei $\mathrm{n}^{\mathrm{o}}$. 26.206, aprovada pelo Congresso Nacional Argentino, em 14 de dezembro de 2006. À Educação Especial o documento destinou quatro artigos (42, 43, 44 e 45). Neles, o público-alvo 
desta modalidade é apresentado de forma genérica. Apesar de indicar que a Educação Especial é destinada a assegurar o direito à educação das pessoas com deficiência, temporária ou permanente, não traz esclarecimentos sobre quais situações se enquadram ou podem ser classificadas como "deficiência". Também não foi definido nesta lei como, onde e quando essa modalidade de ensino deve atuar.

Salienta-se o artigo 44, que, de forma ampla, traz alguns indicativos para a Educação Especial na Argentina. Composto por cinco alíneas $(a, b, c, d \mathrm{e} e)$, todas elas demonstram como as autoridades jurisdicionais podem agir para assegurar o direito à educação das pessoas com deficiência. Nota-se serem orientações gerais, sem delimitações de espaço e tempo, o que, de certa forma, pode ter sido construído intencionalmente, haja vista que as estratégias a serem desenvolvidas possuem suas particularidades que não podem ser moldadas a priori. Assim, o propósito de "posibilitar una trayectoria educativa integral que permita el acceso a los saberes tecnológicos, artísticos y culturales", por exemplo, poderia, em tese, ser operacionalizado de diversas formas, espaços e tempos, ou seja, dentro da sala de aula comum com atividades pedagógicas específicas, por meio de aulas de computação ou outras tecnologias no contraturno ou, ainda, através de utilização de equipamentos como computadores ou tablets no processo de escolarização (ARGENTINA, 2006).

Nesse viés, o Consejo Federal de Educación (CFE) elaborou a Resolución n. 155, de 13 de outubro de 2011, sobre a modalidade da Educação Especial. A resolução define a deficiência a partir do modelo social sustentado pela Organização Mundial da Saúde (OMS) e pelas convenções e princípios de direitos humanos. A deficiência, para este modelo, não é tãosomente uma particularidade do sujeito, e sim o resultado da combinação entre características da pessoa e do contexto social, "en este sentido, la discapacidad es un resultado negativo de la interación entre una condición personal (la deficiência) y el médio (debido a sus barreras)." (ARGENTINA, 2011).

O texto da resolução indica que a escolarização das pessoas com deficiência, permanentes ou temporárias, tem como referência o currículo comum, adotando a inserção na sala de aula comum do ensino regular como uma estratégia de inclusão escolar. Assim, o que se visa alcançar é a escolarização dos alunos com deficiência na sala de aula comum/regular.

De maneira complementar à Resolución n. 155/2011, o CFE editou, em 15 de dezembro de 2016, a Resolución n. 311, responsável por estabelecer as condições para a inclusão escolar no sistema educativo argentino e o acompanhamento das trajetórias escolares dos estudantes com deficiência e, por meio da qual, também aprovou documento sobre a promoção, acreditação, certificação e titulação desses estudantes. Esta resolução reafirma o que foi previsto 
pela Resolución n. 155/2011, ou seja, de que a escolarização deve ocorrer em classes regulares do ensino comum, com suporte de serviços ou apoios específicos, que não são limitados a um rol taxativo. O documento prevê, ainda, extraordinariamente, a escolarização em escolas de Educação Especial em casos cuja complexidade da necessidade educacional específica do aluno o exija.

Sobre o Brasil, foram analisadas a Constituição da República Federativa do Brasil (1988), a Lei de Diretrizes e Bases da Educação Nacional - LDB (n. 9.394/1996), a Resolução CNE/CEB nº. 2/2001 e a Política Nacional de Educação Especial na Perspectiva da Educação Inclusiva (2008).

O texto constitucional vigente fez uma abordagem reduzida. Estabeleceu em seu teor que a educação é direito de todos (artigo 205) e garantiu, por meio do artigo 208, que o Estado forneça Atendimento Educacional Especializado (AEE) para pessoas com deficiência. Apesar dessas inserções, não houve definição sobre o público-alvo da Educação Especial, assim como deixou de indicar o modus operandi do AEE, não sendo preciso sobre o espaço e tempo da escolarização destes indivíduos (MENDES, 2019).

A Educação Especial tem para si, na LDB/1996, um capítulo integrado por quatro artigos $(58,59,59$-A e 60$)$, sendo que no primeiro deles há recomendação para que sua oferta seja na rede regular de ensino. Assim, pelas disposições da LDB/1996, a Educação Especial é uma modalidade de educação escolar, devendo as escolas regulares proverem de serviços de apoio especializados para atender às peculiaridades do alunado da Educação Especial.

A Resolução no. 2/2001, da Câmara de Educação Básica (CEB) do Ministério da Educação (MEC), que instituiu as Diretrizes Nacionais para a Educação Especial na Educação Básica, ampliou significativamente o público-alvo da Educação Especial ao conferir, no artigo $5^{\circ}$, um conceito aberto para "educando com necessidades educacionais especiais" que devem receber recursos e serviços educacionais especiais. A abrangência observada no artigo deixa o público-alvo da Educação Especial bastante vago, podendo englobar todos aqueles com dificuldades de aprendizagem e com comportamentos disruptivos.

No artigo $8^{\circ}$, a norma indica, via de regra, a escolarização dos alunos com necessidades educacionais especiais junto às classes comuns do ensino regular - e, extraordinariamente, em classes e escolas especiais. Prevê ainda a oferta de serviços de apoio pedagógico especializado, tradutores/intérpretes e salas de recursos. Assim, pela resolução, o tempo/espaço da escolarização é o mesmo oferecido para todos os alunos na sala de aula comum do sistema regular de ensino, podendo haver alguma flexibilização, sendo possível também o AEE ser prestado extraclasse. 
O MEC apresentou, no ano de 2008, a Política Nacional de Educação Especial na Perspectiva da Educação Inclusiva (PNEE-EI), com o objetivo de assegurar o acesso, a participação e a aprendizagem dos alunos com deficiência, transtornos globais do desenvolvimento e altas habilidades/superdotação - definidos como público-alvo da Educação Especial - nas classes comuns das escolas de ensino regular. Neste documento, a Educação Especial é reiterada como uma modalidade transversal a todos os níveis, etapas e modalidades de ensino - da Educação Básica à Educação Superior. A escolarização do público-alvo da Educação Especial é requerida nas classes comuns das escolas de ensino regular e o AEE é enfatizado como complementar e/ou suplementar, com oferta no contraturno da escolarização. Em 2009, as Diretrizes Operacionais para o AEE na Educação Básica irão indicar a realização do AEE, prioritariamente, no espaço da sala de recursos multifuncionais.

As análises referentes ao Paraguai sustentaram-se na Constitución de la República del Paraguay (1992), na Ley General de Educación (nº. 1.264/1998), Ley de Educación Inclusiva $\left(\mathrm{n}^{\mathrm{o}} .5 .136 / 2013\right)$ e nos Lineamientos para un Sistema Educativo Inclusivo (2018).

A tutela do direito à educação foi realizada na Constituição paraguaia de modo mais genérico, referindo-se às pessoas com deficiência como excepcionais. Por sua vez, a Ley General de Educación n ${ }^{\circ}$. 1.264, aprovada em 26 de maio de 1998, institui como modalidade de ensino a Educación para Personas con Limitaciones o con Capacidades Excepcionales, sem utilizar o termo pessoas com deficiência, mas enquadrando-as em seu campo de atuação. O conceito, por ser substancialmente aberto, pode viabilizar a criação de políticas flexíveis ou dificultá-las por gerar um público indefinível.

Ao editar a norma, o legislador expressou o interesse de que as atividades da modalidade se desenvolvam, na medida do possível, dentro das instituições educativas comuns. Não há no texto legislativo abordagem sobre tempo da oferta educacional da modalidade.

O esboço sobre a estrutura, organização e funcionamento da modalidade ficou a cargo da Lei $n^{\circ}$. 5.136, de 23 de dezembro de 2013, intitulada de Ley de Educación Inclusiva. De início, a legislação definiu o público ao qual é direcionada como aqueles alunos que apresentam necessidades específicas de apoio educativo, tratando o texto legislativo de elucidar quem são estes alunos. Constata-se que a norma prioriza o atendimento educacional desse alunado no sistema regular de ensino. Com relação aos serviços de apoio e aos ajustes razoáveis, por outro lado, a lei permanece lacunar, não mencionando em quais tempos ou espaços tais ações serão oferecidas.

Recentemente, o governo do Paraguai, com o apoio de outras organizações internacionais, publicou um documento voltado à promoção do sistema educativo inclusivo no 
país, ao qual se deu o nome de Lineamientos para un sistema educativo inclusivo en Paraguay. Este texto apenas reitera as disposições dos documentos anteriores, sobretudo de que a escolarização deva ocorrer no sistema regular de ensino, com o auxílio de serviços de apoio e ajustes razoáveis.

Para a exposição da abordagem contida na documentação uruguaia sobre Educação Especial, seu público-alvo e os espaços/tempos de sua escolarização e de prestação dos serviços especializados, observou-se a Constitución de La República de Uruguay (1967), Ley General de Educación ( $\mathrm{n}^{\circ}$. 18.437/2008), Ley sobre la Protección Integral de Personas con Discapacidad (2010) e Protocolo de Actuación para la Inclusión de Personas con Discapacidad en los Centros Educativos (2017).

A Constitución de La República de Uruguay, promulgada em 1967, não faz menção à Educação Especial, de pessoas com deficiência ou de indivíduos com necessidades educativas especiais. Constata-se também a ausência de abordagem sobre os direitos, em amplo aspecto, das pessoas com deficiência.

Por sua vez, a Ley General de Educación nº ${ }^{\circ}$ 18.437, aprovada em 15 de dezembro de 2008, reconhece a Educación de personas con discapacidades e a define como uma das modalidades da educação formal. No entanto, a legislação é bastante genérica, deixando de pormenorizar os sujeitos compreendidos por esta modalidade de educação, o que faz gerar dúvida de quem se encaixa no conceito de pessoas com "discapacidades". A mesma ausência de esclarecimento atinge aspectos como o espaço e tempo da escolarização e da oferta de serviços especializados.

A Ley n. 18.651, aprovada em 19 de fevereiro de 2010, dispõe sobre la protección integral de personas con discapacidad, apresentando orientações gerais sobre o conceito de deficiência, conforme o modelo social, e um tópico específico sobre o direito à educação da pessoa com deficiência. Recomenda a escolarização dessa população em classes comuns com apoios necessários, porém nada esclarece sobre o espaço e tempo da oferta do atendimento especializado.

Em 20 de março de 2017 foi aprovado pelo presidente uruguaio o Protocolo de Actuación para la Inclusión de Personas con Discapacidad en los Centros Educativos. O documento não indica com clareza como se dará a oferta desta modalidade de educação, especialmente no que diz respeito ao espaço e tempo de aprendizagem para esse público (pessoas com deficiência). No entanto, a leitura sistematizada do plano de atuação permite a compreensão de que os indivíduos serão inseridos no mesmo contexto que os demais, ou seja, no sistema regular de ensino (escolas comuns), promovendo-se para tanto um desenho universal 
e condições de acessibilidade, ficando disponíveis ajudas técnicas para situações de necessidade.

No que diz respeito à Venezuela, os documentos selecionados foram: a Constitución de la República Bolivariana de Venezuela (1999), a Ley Orgánica de Educación (2009) e o documento denominado Conceptualización y Política de Educación Especial para la Atención Educativa Integral de la Población con Necesidades Especiales y/o con Discapacidad (2017).

A Constituição venezuelana, promulgada em 15 de dezembro de 1999, se manifesta sobre a necessidade de dar atenção igualitária a determinados grupos, como as pessoas com necessidades especiais ou com deficiência, porém manteve-se inerte sobre a definição e abrangência da expressão personas con necesidades especiales o con discapacidad.

Em 15 de agosto de 2009 foi publicada a Ley Orgánica de Educación, contudo, nela não houve delineamento sobre a educação para pessoas com necessidades educacionais específicas.

No documento denominado Conceptualización y Política de Educación Especial para la Atención Educativa Integral de la Población con Necesidades Especiales y/o con Discapacidad se encontram normas sobre a Educação Especial. Nota-se que, pelo conectivo utilizado "e/ou", os serviços da modalidade se direcionam ao atendimento de dois grupos: aqueles com necessidades educativas especiais e aqueles com deficiência, ou ainda aqueles sujeitos enquadrados em ambos os grupos ao mesmo tempo. O país também se amparou no modelo social de deficiência.

O documento em estudo aponta que serviços de apoio devem estar disponíveis no contexto do ensino regular. Deixa claro que eles são destinados apenas ao apoio da escolarização, sendo esta competência exclusiva das instituições nas quais as pessoas com deficiência estejam matriculadas. É pouco esclarecedor no que tange ao momento, horário e forma de atendimento desses serviços, ficando subentendido que eles caminharão em concomitância com a proposta pedagógica do ensino regular.

\section{Considerações finais}

O discurso da educação inclusiva tem circulado de forma fluida, lacunar e sintética nos Planos de Ação do SEM nas duas últimas décadas, como um catalisador de uma "educação para todos", visando a integração regional e comercial do bloco. Entre os três primeiros Planos de Ação $(2001-2005 ; 2006-2010 ; 2011-2015)$ constata-se certa preocupação quanto à temática, 
sobretudo no Plano de 2011-2015, porém, o Plano de Ação de 2016-2020, em vigência, recuou, apresentando vagas menções à educação inclusiva.

Com relação à Educação Especial, nos documentos produzidos internamente por cada um dos países membros do MERCOSUL, nota-se certo alinhamento entre eles no que diz respeito à compreensão de que o ambiente mais indicado para a escolarização dos alunos com necessidades educacionais específicas é a classe comum das escolas de ensino regular.

Entretanto, há significativas diferenças nos documentos internos dos países membros do MERCOSUL quanto à definição dos sujeitos compreendidos pela modalidade da Educação Especial. Tampouco há linearidade no que se refere aos espaços e aos tempos em que os serviços de apoio especializados são ofertados. Observa-se, inclusive, que a própria nomenclatura da modalidade educacional que atende pessoas com necessidades educacionais específicas apresenta variações entre os países.

Ainda assim, é possível considerar, por meio da documentação perscrutada, que a Educação Especial nos países membros do MERCOSUL se coaduna com a perspectiva inclusiva que se alastrou por meio dos movimentos globais de universalização da educação impulsionados pela UNESCO. Trata-se de um discurso hegemônico, com efeitos no plano político-econômico, produzido de forma complexa e articulada aos ideários do neoliberalismo, da globalização, do direito humano à educação e do reconhecimento das diferenças dos alunos em processo de escolarização.

\section{REFERÊNCIAS}

AINSCOW, Mel. Tornar a educação inclusiva: como esta tarefa deve ser conceituada? In: FÁVERO, Osmar et al. (Org). Tornar a educação inclusiva. Brasília: UNESCO, p. 11-23, 2009.

ARGENTINA. CFE Resolución n. 155/11. Disponível em: https://archivos.formosa.gob.ar/media/uploads/documentos/documento_1498167262.pd. Acesso em: 13 abr. 2018.

ARGENTINA. Ley n. 26206, de 14 de dezembro de 2006. Ley de Educación Nacional. Disponível em: https://www.argentina.gob.ar/sites/default/files/ley-de-educ-nac58ac89392ea4c.pdf. Acesso em: 13 abr. 2018.

BOBBIO, Norberto. A era dos direitos. Rio de Janeiro: Elsevier, 2004.

MARCONI, Marina de Andrade; LAKATOS, Eva Maria. Fundamentos da metodologia científica. 5. ed. São Paulo: Atlas, 2003. 
MATEUS, Douglas Predo. A efetividade do direito à educação no Brasil e Mercosul: o Tratado de Assunção e a educação. Dissertação (Mestrado em Direito Internacional). Universidade Católica de Santos, Santos. 88 f., 2008.

MENDES, Enicéia Gonçalves. A Política de Educação Inclusiva e o Futuro das Instituições Especializadas no Brasil. Arquivos Analíticos de Políticas Educativas. v. 27, n. 22, 2019.

MERCOSUL. Saiba mais sobre o MERCOSUL. Disponível em: http:// http://www.mercosul.gov.br/saiba-mais-sobre-o-mercosul. Acesso em: 26 maio 2019.

MERCOSUL. Plano de Ação do Setor Educacional do Mercosul 2016-2020. Instituto Nacional de Estudos e Pesquisas Educacionais Anísio Teixeira, 2016. Disponível em: http://edu.mercosur.int/pt-BR/plano-2011-2015/160-plano-de-acao-2016-2020.html. Acesso em: 21 ago. 2018.

SHIROMA, Eneida Oto; MORAES, Maria Célia Marcondes de; EVANGELISTA, Olinda. Política educacional. 4. ed. Rio de Janeiro: Lamparina, 2011.

SOUZA, Kellcia Rezende. Direito à educação nos países membros do Mercosul: um estudo comparado. 346f. Tese (Doutorado em Educação). Universidade Estadual Paulista Júlio de Mesquita Filho, Araraquara. 2017.

\section{Como referenciar este artigo}

ICASATTI, A. V.; NOZU, W. C. S. Abordagem político-normativa da educação especial nos países membros do Mercosul. Revista Ibero-Americana de Estudos em Educação, Araraquara, v. 15, n. 2, p. 508-521, abr./jun. 2020. e-ISSN: 1982-5587. DOI: https://doi.org/10.21723/riaee.v15i3.12753

Submetido em: 25/03/2019

Revisões requeridas: 30/05/2019

Aceito em: 20/06/2019

Publicado em: 20/02/2020 